\title{
Impact of NEXUS Low-Risk Criteria on Cervical Injuries in a Turkish Tertiary-Care Hospital
}

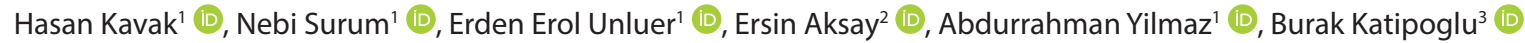 \\ 'Department of Emergency, Usak University School of Medicine, Usak, Turkey \\ ${ }^{2}$ Department of Emergency, Dokuz Eylul University School of Medicine, Izmir, Turkey \\ ${ }^{3}$ Department of Emergency, Health Sciences University Ankara Training and Research Hospital, Ankara, Turkey
}

Cite this article as: Kavak H, Surum N, Unluer EE, Aksay E, Yilmaz A, Katipoglu B. Impact of NEXUS Low-Risk Criteria on Cervical Injuries in a Turkish Tertiary-Care Hospital. Eurasian J Emerg Med. 2018; 17 (3): 113-7.

\begin{abstract}
Aim: In the present study, we aimed to determine the amount of unnecessary X-ray graphics that could lead to cost-load and radiation side effects using NEXUS LowRisk Criteria (NLC) that was applied and evaluated in patients with cervical spine trauma in the Izmir Ataturk Training and Research Hospital's emergency department.

Materials and Methods: Between June 2010 and September 2010, the trauma patients admitted to the emergency department were evaluated retrospectively. The age, sex, NLC, mechanisms of trauma, radiological imaging, cost, radiation load, and degree of cervical injuries were assessed.

Results: In the present study, 1317 patients with a possible cervical spine injury were included. It was confirmed that the numbers of excluded and included patients according to NLC were 1014 and 303, respectively. In excluded patients, 479 (36.3\%) did not have any radiology, but in 535 (52.7\%) of them, unnecessary radiological imaging studies were administered. The trauma mechanism was crash at the same level in 310 (23.5\%) of the total and 267 (26.3\%) of the excluded patients. In addition, in-vehicle traffic accident was observed in 64 (21.1\%) included patients. It was found that the number of cervical spine injuries was four in the excluded and 10 in the included groups, which was confirmed according to NLC.
\end{abstract}

Conclusion: The increase in the use of NLC leads to a decrease in both the cost and amount of radiation exposure in patients and health workers. In addition, the number of cancers due to iatrogenic etiologies in humans will be lower.

Keywords: NEXUS low-risk criteria, trauma, cervical spine

\section{Introduction}

Cervical spine traumas are among the most serious injuries among trauma patients. In the United States and Canada, 13 million trauma patients annually are at risk for damage to the cervical spine. Cervical spinal injury is found in $2 \%-3 \%$ of patients with multiple trauma (1). Routine cervical radiography is performed to exclude cervical injuries, but few of these patients have cervical vertebrae injuries. For this reason, it can be predicted that cervical radiography may have been taken unnecessarily in some patients.

Unnecessary graphs taken in patients with suspected cervical trauma put a financial burden on patients and insurance institutions.
Patients are subjected to cervical immobilization, which is a disturbing intervention for a long time, due to the absence of indications in their wishes for radiographic imaging. An emergency service that is crowded and heavy in workload causes patient dissatisfaction andloss of work power (2).

The National Emergency X-Radiography Utilization Study (NEXUS) Low-Risk Criteria (NLC) has been developed for patients with suspicious cervical trauma with the goal of reducing unnecessary radiographic requests and improving standard imaging indications. These criteria demonstrate the indications for cervical direct $\mathrm{X}$-ray in trauma patients with the risk of cervical injuries (2).

ORCID IDs of all authors: H.K. 0000-0002-1496-5212; N.S. 0000-0003-2951-2352; E.E.U. 0000-0003-0334-7440; E.A. 0000-0002-3249-2420; A.Y. 0000-0001-8024-8951; B.K. 0000-0002-4347-6258. 
In the present study, we investigated the number of unnecessary vertebrae graphs and the cost and radiation burden generated as a result of the application and evaluation of NLC in cervical trauma patients who presented to our emergency department.

\section{Materials and Methods}

\section{Center of the study}

A retrospective cross-sectional study was conducted at Izmir Ataturk Training and Research Hospital Emergency Medicine Clinic. Izmir Ataturk Training and Research Hospital is a third-level health institution, and the number of patients that apply to the emergency service annually is approximately 210,000 . Approval was obtained from the ethics committee of Izmir Ataturk Training and Research Hospital for the study.

\section{Sample of the study}

The sample of the study comprised patients over the age of 18 years who applied within the first $48 \mathrm{~h}$ after trauma between June 2010 and September 2010. The criteria for inclusion or exclusion are given in Table 1.

Table 1. Study sample criteria

\begin{tabular}{|l|l|}
\hline \multicolumn{1}{|c|}{$\begin{array}{l}\text { Inclusion criteria } \\
\text { for the study }\end{array}$} & \multicolumn{1}{c|}{$\begin{array}{c}\text { Exclusion criteria } \\
\text { for the study }\end{array}$} \\
\hline 1. Patients over 18 years old & 1. Patients under the age of 18 \\
\hline $\begin{array}{l}\text { 2. Patients whose consciousness } \\
\text { state is open, co-operative, and } \\
\text { oryante (GCS=15/15) }\end{array}$ & 2. Pregnancy \\
\hline $\begin{array}{l}\text { 3. Patients with acute blunt } \\
\text { head trauma or blunt neck } \\
\text { trauma or both }\end{array}$ & $\begin{array}{l}\text { 3. Patients with penetrating } \\
\text { stab wounds on the neck }\end{array}$ \\
\hline $\begin{array}{l}\text { 4. Whether or not a patient has } \\
\text { pain in the neck area; patients } \\
\text { who cannot be treated remotely } \\
\text { and whose injury to the head/ } \\
\text { neck area above the clavicle } \\
\text { is detected }\end{array}$ & $\begin{array}{l}\text { 4. Patients with cervical injury } \\
\text { story }\end{array}$ \\
\hline
\end{tabular}

Table 2. NEXUS low-risk criteria

The following criteria are indicated for radiographic imaging of cervical vertebrae in trauma patients who do not meet all of them:

- Normal alertness

- No midline cervical tenderness

- No intoxication

- No focal neurological deficit

- No painful distracting injuries
Nexus Low-Risk criteria are given in Table 2 (2). Patients were divided into two groups according to these criteria. The first group comprised patients who did not require any imaging modality (physical examination and severe cervical trauma excluded), and the second group included patients who did not have NLC (advanced physical examination and severe cervical trauma could not be ruled out) because of low-risk criteria. Both groups were examined in terms of trauma mechanisms.

The examination cost of the patients who underwent advanced imaging methods when they were included in group 1 and the radiation burden they received were also studied.

The relationship between NLC and vertebrae injury was investigated in group 2 patients.

\section{Data collection}

Data of the patients with a potential head trauma were screened with the International Classification of Diseases (ICD) 10 diagnostic codes from the hospital automation system (Scanned ICD Codes: S00-03, S06-07, S09-14, S16-19, V00-99, W01-19, W50-55, W76, X70, X81, Y00$04, Y 20, Y 29-32$, and Y35.3).

Patients included in the hospital automation system science study module were identified by defining NLC, trauma mechanism, cost burden, and radiation burden.

Cervical vertebrae-computerized tomography $(\mathrm{CT})$ and graphs of the patients were interpreted by our radiology specialist physicians. The radiation dose of patients exposed to direct X-rays was 0.12 milliSievert ( $\mathrm{mSv}$ ), and the radiation dose of patients undergoing $\mathrm{CT}$ was calculated to be $5 \mathrm{mSv}$. According to the NLC, group 1 represented as pathologic results eventhough belong to the low risk group were reached via telephone and were asked whether they had any complaints about cervical trauma.

\section{Statistical analysis}

All data obtained from the study were recorded in the standard program Statistical Package for Social Sciences (SPSS Inc.; Chicago, IL, USA) for Windows 16 and evaluated. Numerical variables were summarized as mean $\pm S D$ and categorical variables as number and percentage. ANOVA (Analysis of variance) test was used for age and gender comparisons in groups 1 and 2, and Chi-square and Fisher's exact tests were used in other groups.

\section{Results}

International Classification of Diseases diagnostic codes were obtained from 5057 patients with possible neck trauma. 3740 patients were excluded from the study because of the patient's age of under 18 years old, incomplete documents and incompatible clinical findings (single extremity injury, cutter or penetrant injury, chest or abdominal trauma, etc.). Of the remaining patients, our study group comprised 1317 (26.0\%) patients with possible head or neck trauma.

Among these patients, 1014 (77.0\%) patients were included in the group (group 1) excluding possible cervical injuries as they met NLC. The remaining 303 patients (23.0\%) were included in group 2 because they did not meet NLC. 
Table 3. Trauma mechanisms

\begin{tabular}{|l|c|c|c|}
\hline Mechanism & $\begin{array}{c}\text { Group 1 } \\
\mathbf{n}(\%)\end{array}$ & $\begin{array}{c}\text { Group 2 } \\
\mathbf{n}(\%)\end{array}$ & $\begin{array}{c}\text { Total } \\
\mathbf{n}(\%)\end{array}$ \\
\hline Same-level fall & $267(26.3)$ & $43(14.2)$ & $310(23.5)$ \\
\hline In-vehicle traffic accident & $174(17.2)$ & $64(21.1)$ & $238(18.1)$ \\
\hline $\begin{array}{l}\text { Stabbing in the head with } \\
\text { an unknown object }\end{array}$ & $184(18.1)$ & $29(9.6)$ & $213(16.2)$ \\
\hline Motorcycle accident & $83(8.2)$ & $53(17.5)$ & $136(10.3)$ \\
\hline Hitting the head to/with an object & $82(8.1)$ & $3(1.0)$ & $85(6.5)$ \\
\hline Pedestrian traffic accident & $58(5.7)$ & $23(7.6)$ & $81(6.2)$ \\
\hline Impact with blunt object & $68(6.7)$ & $9(3.0)$ & $77(5.8)$ \\
\hline $\begin{array}{l}\text { Falling from 1 to 3 m high } \\
\text { or 5-15 steps }\end{array}$ & $26(2.6)$ & $31(10.2)$ & $57(4.3)$ \\
\hline $\begin{array}{l}\text { Falling from <1 m elevation } \\
\text { or <5 steps }\end{array}$ & $30(3.0)$ & $10(3.3)$ & $40(3.0)$ \\
\hline Falling from >3 m or 15 steps & $7(0.7)$ & $18(5.9)$ & $25(1.9)$ \\
\hline Others & $35(3.4)$ & $20(6.6)$ & $55(4.2)$ \\
\hline TOTAL & $1014(100)$ & $303(100)$ & $1317(100)$ \\
\hline
\end{tabular}

In total, 841 (63.9\%) patients of the study group were male, and the mean age was $41.2 \pm 18.8$ years $(40.9 \pm 19.0$ years for group 1 and $42.3 \pm 18.2$ years for group 2 ).

When examined by gender, in-vehicle traffic accidents $(n=167$, $19.9 \%)$ and hitting the head of the unidentified object $(n=150,17.8 \%)$ in men and same-level falls ( $n=180,37.8 \%)$ and in-vehicle traffic accidents ( $n=71,14.9 \%)$ in women were among the most common causes. When trauma mechanisms were examined according to the age group, the most common injury mechanism in the age groups of 1820 years and $21-40$ years was in-vehicle traffic accidents $(22.7 \%$ and $22.0 \%$, respectively). In the 41-60- and over 60-year-old groups, it was determined that the most common mechanism was falling from the same level (22.3\% and $49.1 \%$, respectively) (Table 3 ).

\section{Cervical vertebrae injuries}

Cervical vertebrae injuries that were not included in group 1 are given in Table 4. The patients with cervical injuries in group 1 were called by telephone approximately 4 months later. These four patients were found to have no complaints or deficits by themselves or their relatives.

Table 4. Cervical vertebra injuries that failed to be detected in group 1

\begin{tabular}{|l|l|l|l|l|}
\hline & Age, Gender & Mechanism & Injury type & Prognosis \\
\hline 1 & $20, \mathrm{M}$ & Pedestrian traffic accident & C3 vertebrae mild anterolystesis & No complaints. There is no deficit. \\
\hline 2 & $55, \mathrm{M}$ & Impact with blunt object & C6-7 disc prolusion and minimal cord pressure & No complaints. There is no deficit. \\
\hline 3 & $22, \mathrm{M}$ & In-vehicle traffic accident & C6 vertebrae pedicle posterior fracture & No complaints. There is no deficit. \\
\hline 4 & $77, \mathrm{~F}$ & Same-level fall & Suspicious atlantoaxial dislocation & No complaints. There is no deficit. \\
\hline
\end{tabular}

Table 5. Cervical vertebra injuries detected in group 2

\begin{tabular}{|c|c|c|c|c|c|c|}
\hline & Age, Gender & Mechanism & Injury type & Findings & Treatment & Hospitalization \\
\hline 1 & $63, M$ & In-vehicle traffic accident & C2 left neural arcus fracture & SPS & Internal fixation & Yes \\
\hline 2 & $19, \mathrm{M}$ & In-vehicle traffic accident & Corpus C6 fracture & SPS & Internal fixation & Yes \\
\hline 3 & $49, \mathrm{~F}$ & In-vehicle traffic accident & $\begin{array}{l}\text { C5-C6 vertebrae corpus } \\
\text { fracture }\end{array}$ & $\begin{array}{l}\text { Consciousness } \\
\text { disorder, painful } \\
\text { distracting injury }\end{array}$ & None & Yes \\
\hline 4 & $32, \mathrm{~F}$ & In-vehicle traffic accident & $\begin{array}{l}\text { C3 arcus, C4 pedicle, } \\
\text { and lamina fracture }\end{array}$ & $\begin{array}{l}\text { SPS, FND, painful } \\
\text { distracting injury }\end{array}$ & Internal fixation & Yes \\
\hline 5 & $26, M$ & Motorcycle accident & C2 left neural arcus fracture & $\begin{array}{l}\text { SPS+FND(top left, } \\
\text { extremity muscle } \\
\text { power 4/5) }\end{array}$ & Internal fixation & Yes \\
\hline 6 & $19, \mathrm{M}$ & Motorcycle accident & $\mathrm{C} 2, \mathrm{C} 5$, and $\mathrm{C} 6$ corpus fracture & FND (paraplegic) & None & Yes \\
\hline 7 & $18, M$ & Motorcycle accident & $\begin{array}{l}\text { C1 anterior arcus and C6 } \\
\text { corpus fracture }\end{array}$ & SPS & None (exitus) & Yes \\
\hline 8 & $42, \mathrm{M}$ & Plunge & C7 corpus fracture & SPS & Internal fixation & Yes \\
\hline 9 & $18, M$ & Plunge & $\begin{array}{l}\text { C5 corpus and both two } \\
\text { neural arcus fractures }\end{array}$ & $\begin{array}{l}\text { FND (lower extremity } \\
\text { sensation, upper- } \\
\text { lower extremity } \\
\text { motor loss) }\end{array}$ & Internal fixation & Yes \\
\hline 10 & $47, M$ & $\begin{array}{l}\text { Falling from }>3 \mathrm{~m} \text { or } \\
15 \text { steps }\end{array}$ & C6-C7 lamina fractures & $\begin{array}{l}\text { Painful distracting } \\
\text { injury }\end{array}$ & $\begin{array}{l}\text { Yok (toracal } \\
\text { internal fixation) }\end{array}$ & Yes \\
\hline
\end{tabular}


Cervical vertebrae injuries were detected in 10 patients in group 2 . This group is shown in Table 5. Eight of the injuries occurred in males, whereas two occurred in females. Four (18.2\%) patients in the 18-20 year age group, two (1.4\%) patients in the $21-40$ year age group, three patients (3.3\%) in the 41-60 year age group, and one (2.0\%) in the 61 year and older age group had cervical vertebrae injuries $(p=0.001)$.

Cervical vertebrae injuries were found in one $(1.7 \%)$ of the unconscious patients and in nine patients (3.7\%) without consciousness impairment $(p=0.693)$. Cervical vertebrae injuries were detected in six $(10.9 \%)$ of the patients with midline cervical tenderness and in three $(1.6 \%)$ of the patients without midline cervical tenderness $(p=0.005)$. Cervical vertebrae injuries were not detected in patients with intoxication status, but they were detected in nine (4.5\%) of the non-intoxication patients.

Cervical vertebrae injuries were found in four $(36.4 \%)$ of the patients with a focal neurological deficit and in five of the patients without a focal neurological deficit $(2.1 \%)(p=0.001)$. Cervical vertebrae injuries were found in two (1.3\%) of the patients with a distracting painful injury, whereas it were found in seven $(7.0 \%)$ of the non-injured patients $(p=0.032)$.

Patients with multiple criteria within NLC were excluded because of the incidence of cervical vertebrae injuries and inadequate patient groups.

\section{Unnecessary performed radiological imaging}

Of the 1014 patients in group 1, 535 (52.7\%) underwent unnecessary radiological imaging; $423(79.1 \%)$ had two-way cervical vertebrae; cervical vertebrae CT was performed in seven patients (1.4\%); a twoway cervical vertebrae graph and CT were performed in 45 patients $(8.4 \%)$; one $(0.2 \%)$ patient underwent two-way cervical vertebrae graph and cervical MRI; one (0.2\%) patient underwent two-way cervical vertebrae graph, cervical vertebrae $\mathrm{CT}$, and cervical MRI; and in the remaining two $(0.4 \%)$ patients, two-way cervical vertebrae and one cervical CT scan were performed.

From the hospital automation system, it was determined that the above unnecessary radiological examinations resulted in a financial burden of Turkish lira (TL) 55.366 in hospital costs. Patients were exposed to an additional dose of approximately $331.88 \mathrm{mSv}$. It was found that $424(79.2 \%)$ patients were exposed to radiation doses to $0.12 \mathrm{mSv}$, seven (1.4\%) patients to $5 \mathrm{mSv}, 46$ (8.5\%) patients to 5.12 $\mathrm{mSv}$, and two (0.4\%) patients to $5.24 \mathrm{mSv}$.

\section{Discussion}

In the present study, patients were exposed to approximately 331.88 $\mathrm{mSv}$ total radiation in effective dose. The distribution of these doses was $5.24 \mathrm{mSv}$ in 424 patients (79.2\%), $5 \mathrm{mSv}$ in seven patients (1.4\%), $5.12 \mathrm{mSv}$ in 46 patients (8.5\%), and $5.24 \mathrm{mSv}$ in two patients $(0.4 \%)$. The risk of developing lifetime cancer in these patients increased by 1 per 10.000 .

Economically, there was an extra cost of TL 55.366 in total. However, when considering the expenditure for all trauma patients across the country, it is clear how high the figures will be. Approximately 50,000 patients were admitted to our emergency department from June 1, 2010, to September 1, 2010. According to the data from The Ministry of Health of the Republic of Turkey, the annual number of registrations to emergency services in Turkey is approximately $60,000,000$. It has been observed that unnecessary cervical imaging costs about TL 60 million annually. With a similar calculation, these patients are exposed to about $400,000 \mathrm{mSv}$ of radiation in total, which is equal to the amount of radiation received by 130,000 people per year from nature.

Approximately 800.000 cervical vertebrae graphs per year are required in patients with blunt neck trauma in the United States, resulting in a cost of approximately US\$ 180 million. Consequently, 10,000 cervical vertebrae injuries were detected; the remaining 790,000 (98\%) were negative expense costs and radiation exposure for the patients. NLC have been tried to be developed for those with a minimal risk of injury to the cervical vertebrae, which constitutes the vast majority. The application of these criteria will reduce the number of radiographs to one-third, which will reduce the cost by approximately US\$ 60 million, the radiation dose, and radiation-induced morbidity and mortality (3). In addition, the reasons for the development of NLC include the need for diagnostic testing with standard indications and a reduction in patient immobilization and the waiting period in emergency care, thus reducing the workload. In addition, any unnecessary radiographs and examinations required from patients cause the more vital problems of the patients to be ignored and the patients to be transported to distant centers, such as CT and graph centers, which are not controlled from the emergency room. This procedure also makes it difficult to control patients who are not stable, carrying the risk of rapid detoriation. This also-delays -to transfer to other services or hospitals for further care of these patients.

Hoffman et al. (2) published a brief prospective study in 1992 on low-risk criteria. They planned a large-scale NEXUS study in 1998 and published the work method. In 2000, they tested and published the validity of the completed work. In that study, NLC was found to be $99.6 \%$ sensitive and $12.9 \%$ specific for cervical trauma in 34,069 patients. Eight of the 818 patients with NLC cervical vertebrae injuries failed to be detected. Clinically non-sequela or asymptomatic patients were -may cause misdiagnosis. These patients recovered without surgical treatment.

In a study on the use of NLC in Australia, nurses and doctors were compared based on the time of completion of the work. The study revealed that NLC is easily applicable by nurses and assistant health personnel for low-risk trauma patients (4).

In a study conducted in the UK, it was stated that the shortening of the immobilization period of the patients showed a significant improvement in patient care because the NLC allowed accident and triage nurses to safely remove the neck and trauma boards (5).

The application of NLC, Stiell et al. (2) found that 2347 (28.4\%) of 8283 patients avoided radiographic imaging (1). In the study by Hoffman et al. (2), 4309 of 34,069 patients (12.6\%) avoided radiological imaging, whereas in a study by Dickinson et al. (6), 2779 (31.1\%) of 8924 patients avoided radiological imaging (6). Radiologic imaging was applied to 535 (52.7\%) patients, although we excluded 1014 patients (77.0\%) from 1317 patients in our study. 
In a study by Hoffman et al. (2), 34,069 patients had a mean age of 37 years, and $2.5 \%$ of these patients were 8 years of age or younger; the mean age of $818(2.4 \%)$ patients with cervical vertebrae injuries was 40 years, and $1.3 \%$ of these were 8 years old or younger. In the present study, the mean age of 1317 patients was $41.2 \pm 18.8$ years (not included under 18), and 14 (1.1\%) patients had cervical vertebrae injuries; their average age was $36.1 \pm 19.4$ years. In addition, in the study by Hoffman et al. (2), they misinterpreted eight (0.02\%) patients with cervical vertebrae injury of 34,069 patients, whereas our study passed over four (0.3\%) of 1317 patients. Stiell et al. (1) found that the mean age was $37.6 \pm 16$ years and that $4328(52.3 \%)$ were males; the mean age of 8924 patients was $36.7 \pm 16$ years, and 4600 (51.5\%) were males in the study by Dickinson et al. (6) In the present study, 841 patients (63.9\%) were male.

Dickinson et al. (6) reported the most common trauma mechanism in their study as in-vehicle traffic accidents (1). In the present study, falling from the same level was the most common trauma mechanism. The reason for this may be because Dickinson et al. (6) studies were conducted in the same centers. In addition, because the patient population was at the age of over 16 years, there may have been an increase in the number of in-vehicle accidents due to greater motor vehicle use and more dangerous driving. In general, spinal injuries in the cervical region are the most common in-vehicle accidents (7).

In a study by Paykin et al. (8), 4035 patients who were older than 65 years were analyzed; 468 patients were diagnosed with cervical spine fractures, of whom 21 were determined to be NEXUS-negative. The NEXUS criteria were performed with a sensitivity of $94.8 \%$ in complete case analysis in older blunt trauma patients.

Denver et al. (9) performed the NEXUS criteria in 169 patients and found that this criteria demonstrated $81.8 \%$ sensitivity and a $95.9 \%$ negative predictive value in detecting any cervical spine injury.

\section{Study limitations}

Although anterior-posterior, lateral, and odontoid views of the cervical spine radiography series are required for the determination of cervical trauma, we could not achieve the odontoid views of our patients retrospectively. Based on this limitation, it is possible that there were some missed fractures in both the study groups. Particularly in group 2, those who cannot be excluded by the NEXUS criteria, we were able to achieve MRIs, CTs, and both MRI and CT of the patients (94, 3, and 3, respectively). Ordered radiographic tests were officially reported by radiologists in different hospitals, and this issue limited the external validity of the study.

\section{Conclusion}

Although the academic environment of emergency medicine in our country is high on the NLC awareness level, research has not re- vealed how much of these rules are applied in everyday practice. The increased practical application of NLC will reduce the cost and radiation exposure of patients and healthcare personnel.

Ethics Committee Approval: Ethics committee approval was received for this study from the Ethics Committee of Izmir Ataturk Training and Research Hospital (Date: 13.07.2010 Decision Number: 10).

Informed Consent: Informed consent was not taken from patients due to the retrospective nature of the study.

Peer-review: Externally peer-reviewed.

Author Contributions: Concept - E.E.U.; Design - H.K., E.A.; Supervision E.E.U., E.A.; Resources - H.K., N.S., E.E.U.; Materials - H.K., N.S., B.K.; Data Collection and/or Processing - H.K., N.S., A.Y.; Analysis and/or Interpretation - H.K., E.A., B.K.; Literature Search - H.K., A.Y.; Writing Manuscript - H.K., A.Y., B.K.; Ciritical Review - E.E.U., E.A.

Conflict of Interest: The authors have no conflict of interest to declare.

Financial Disclosure: The authors declared that this study has received no financial support.

\section{References}

1. Stiell IG, Clement CM, McKnight RD, Brison R, Schull MJ, Rowe BH, et al. The Canadian C-spine rule versus the NEXUS low-risk criteria in patients with trauma. N Engl J Med. 2003; 349: 2510-8. [CrossRef]

2. Hoffman JR, Mower WR, Wolfson AB, Todd KH, Zucker MI. Validity of a set of clinical criteria to rule out injury to the cervical spine in patients with blunt trauma. National Emergency X-Radiography Utilization Study Group. N Engl J Med. 2000; 343: 94-9. [CrossRef]

3. Hoffman JR, Wolfson AB, Todd K, Mower WR. Selective cervical spine radiography in blunt trauma: Methodology of the National Emergency X-Radiography Utilization Study (NEXUS). Ann Emerg Med. 1998; 32: 461-9. [CrossRef]

4. Meek R, McGannon D, Edwards L. The safety of nurse clearance of the cervical spine using the National Emergency X-radiography Utilization Study low-risk criteria. Emerg Med Australas. 2007; 19: 372-6. [CrossRef]

5. Pitt E, Pedley DK, Nelson A, Cumming M, Johnston M. Removal of C-spine protection by $A \& E$ triage nurses: a prospective trial of a clinical decision making instrument. Emerg Med J. 2006; 23: 214-5. [CrossRef]

6. Dickinson G, Stiell IG, Schull M, Brison R, Clement CM, Vandemheen KL, et al. Retrospective application of the NEXUS low-risk criteria for cervical spine radiography in Canadian emergency departments. Ann Emerg Med. 2004; 43: 507-14. [CrossRef]

7. Erdogan MO, Demir SA, Kosargelir M, Colak S, Ozturk E. Local differences in epidemiology of traumatic spinal injuries. Ulus Travma Acil Cerrahi Derg. 2013; 19: 49-52. [CrossRef]

8. Paykin G, O'Reilly G, Ackland HM, Mitra B. The NEXUS criteria are insufficient to exclude cervical spine fractures in older blunt trauma patients. Injury. 2017; 48: 1020-4. [CrossRef]

9. Denver D, Shetty A, Unwin D. Falls and Implementation of NEXUS in the Elderly (The FINE Study). J Emerg Med. 2015; 49: 294-300. [CrossRef] 